\title{
On the stability of rock armored rubble mound structures
}

\author{
Amir Etemad-Shahidi ${ }^{* a, b}$, Meysam Balic and Marcel R.A. van Gent ${ }^{\mathrm{d}}$ \\ aSchool of Engineering and Built Environment, Griffith University, QLD, 4222, Australia \\ ${ }^{\mathrm{b} S c h o o l}$ of Engineering, Edith Cowan University, WA, 6027, Australia \\ *Corresponding Author: a.etemadshahidi@griffith.edu.au \\ ${ }^{c}$ PTP consulting company, Tehran, Iran \\ ${ }^{\mathrm{d} D e p a r t m e n t ~ o f ~ C o a s t a l ~ S t r u c t u r e s ~ \& ~ W a v e s, ~ D e l t a r e s, 2600 ~ M H ~ D e l f t ~}$
}

The Netherlands

\begin{abstract}
Estimation of the required armor size is a major task in the design of coastal structures under wave loading such as breakwaters and revetments. Several semi-empirical formulas have been developed for this purpose. However, these formulas are often either limited to certain water depth conditions or do not incorporate the permeability of the structure in an appropriate way. The main objectives of this study are to (a) develop a unified physically sound formula for the estimation of the required rock size in all relevant water depth conditions and (b) to relate the effects of the permeability of the structure directly to physical parameters. To achieve these, first a comprehensive data base of deep and shallow water experiments within the design conditions was built. Then physical reasoning along with a robust data mining approach, i.e. M5 model tree, were used to develop formulas for armor stability. In the stability formula, wave characteristics such as the significant wave height and spectral energy mean period $\left(T_{m-1,0}\right)$ are invoked while the permeability is incorporated using the ratio between the size of the core material and the armor stones. Accuracy metrics such as discrepancy ratio and scatter index indicated high performance of the model in different conditions. Finally, a probabilistic formula and some guidelines are provided for practicing engineers.
\end{abstract}


Keywords: breakwater; stability number; M5 model tree; permeability; shallow water; damage level

\section{Introduction}

Estimation of the hydraulic stability of rubble mound structures and selecting the required rock size is a common practice for coastal engineers. The formulas given in design manuals such as Rock Manual (2007) and CEM (2011) are mostly empirical. Using regular wave tests, Hudson $(1958,1959)$ derived a simple stability formula of which a modified version for irregular waves is still the state-of-the-art stability formula for concrete armor units. However, effects of parameters such as wave period and duration of storm were not included in this formula, although the occurrence of wave breaking or not was found to affect the stability. Ahrens (1970, 1975) and Thompson and Shuttler (1975), hereafter TS, conducted a large number of tests with regular and irregular waves on rock armored slopes to investigate effects of many parameters. TS noticed that the type of wave breaking, which depends on the wave period influences the stability. The results of TS were reanalyzed by the Van der Meer $(1988 \mathrm{a}, \mathrm{b})$, hereafter $\mathrm{VdM}$, in order to quantify the importance of the storm duration by including the number of waves. By conducting a large number of experiments, VdM also quantified the effects of many parameters on the damage level $\left(S_{d}\right)$. The wave properties were characterized by the significant height, $H_{s}$ and the mean period $T_{m}$. However, the experiments by $\mathrm{VdM}$ were mostly focused on deep water condition. To provide more insight into shallow water conditions, which are more common for rock armored slopes, Smith et al. (2002) and Van Gent et al. (2003), hereafter VSK, conducted several tests with both single and double peaked wave energy spectra. VSK noticed that the wave period can be better characterized by $T_{m-1,0}$, the spectral mean energy period. VSK modified the VdM formula to extend the field of application to shallow water conditions. In addition, VSK also developed a relatively simple stability formula which quantifies the structure permeability in physical parameters using the ratio of armor size to that of core. This relatively simple formula does not include the wave 
period. Vidal et al. (2006), hereafter VML, also conducted physical model tests and suggested to use the parameter $H_{50}$, the average wave height of the 50 highest waves, to characterize the wave height and VML also provided a stability formula.

With the development of computers and data mining approaches, several authors (e.g. Mase, 1995, Kim and Park, 2005, Erdik, 2009) using data set of VdM, attempted to improve the accuracy of stability prediction using different approaches. However, the developed models are rather opaque and do not provide insight into the most relevant processes. Hence, Etemad-Shahidi and Bonakdar (2009) used M5 model tree to provide transparent formulas for a more accurate estimation of stability. Their results were further improved by including database of VML to that of $\mathrm{VdM}$ which resulted in formulas using the parameter $H_{50}$ (Etemad-Shahidi and Bali, 2012; hereafter EB). However, similar to most of the previous studies, the used data sets were mostly limited to deep water, and the permeability was characterized by nominal ones suggested by VdM.

The main goal of this study is to provide a unified design formula for stability of rock armored rubble mound structures in both shallow and deep waters conditions and resolve the following issues: (a) lack of physical justification for the functional form and role of the nominal permeability in VdM's type formulas, and (b) inconsistency between deep and shallow water stability formulas. To achieve this, first a comprehensive database of physical model tests with irregular waves, including those of TS, VdM, VML and VSK laboratory data is provided. Then, using physical arguments and data M5 mining approach, a compact formula is developed to estimate the stability number for both deep and shallow conditions using physical parameters describing the permeability of the structure.

\section{Background}

The damage to the armor layer is commonly characterized by damage level, $S_{d}=A_{e} / D^{2}{ }_{n 50}$ where $A_{e}$ is the eroded area, $D_{n 50}=\left(M_{50} / \rho_{a}\right)^{1 / 3}$ is the nominal rock median, and $\rho_{a}$ is the rock 
armor density. Hudson (1959) conducted tests with regular waves on structures with no filter layer and slopes from 1:5 to 1:1.25 in deep and non-deep conditions. Hudson (1959) formula is:

$$
N_{s}=\frac{H_{s}}{\Delta D_{n 50}}=\left(K_{D} \cot \alpha\right)^{1 / 3}
$$

Where $N_{s}$ is the stability number, $H_{s}$ is the significant wave height, $\alpha$ is the structure front angle, $\Delta=\rho_{a} / \rho_{w}-1$ is relative buoyant density and $\rho_{w}$ is water density. The stability coefficient, $K_{D}$, incorporates the effects of armor type and safety factor, and it varies from 2 (1.6) for breaking waves to 4 (2.8) for non-breaking waves hitting the trunk (head) of a breakwater. The formula was initially developed for no damage, defined as $1 \%$ removal of armor units (Hudson, 1959). Medina et al. (1994) compared different damage definitions and showed that no damage is nearly equivalent to $S_{d}$ of 2 . Hudson (1959) formula was later modified as (Rock Manual, 2007):

$$
N_{s}=\frac{H_{s}}{\Delta D_{n 50}}=0.7\left(K_{D} \cot \alpha\right)^{1 / 3} S_{d}^{0.15}
$$

In Hudson's formula effects of the permeability, the wave period, the number of waves (storm duration) and wave breaking type were omitted.

The effects of wave period and breaking type were first noticed by Ahrens $(1970,1975)$. Using regular waves and impermeable ripraps with $2.5 \leq \cot \alpha \leq 5.0$, Ahrens $(1970,1975)$ observed that $N s$ depends on the structure slope and has a minimum value at an Iribarren number around 2.0. This was later used by $\mathrm{VdM}$ formulas for surging and non-surging waves. The importance of the number of waves, $N_{w}$ was recognized by Thompson and Shuttler (1975). Using random waves, TS noticed that $S_{d} \sim N_{w}{ }^{0.5}$. The TS tests were focused on plunging waves with low Iribarren numbers. TS reported the number of displacement units eroded from a of $9 D_{n 50}$ width of slope, $N_{d}$ where $S_{d}=0.18 N_{d}$.

VdM conducted irregular wave tests, mostly in deep water with $h / H_{s}>3$ where $h$ is the toe (local) water depth. VdM introduced a so-called nominal permeability parameter $P$ ranging 
from 0.1 for an impermeable structure to 0.6 for a homogenous one. The VdM formulas (Van der Meer , 1988b; Rock Manual, 2007) are:

$$
\begin{array}{llrl}
N_{s}=6.2 S_{d}^{0.2} P^{0.18} N_{w}^{-0.1} \xi_{m}^{-0.5} \quad \text { If } & \xi_{m}<\xi_{m c} \quad \text { or } & \cot \alpha \geq 4 \text { plunging } \\
N_{s}=1.0 S_{d}^{0.2} P^{-0.13} N_{w}^{-0.1} \xi_{m}^{p} \cot ^{0.5} \alpha & \text { If } \quad \xi_{m} \geq \xi_{m c} \quad \text { and } \cot \alpha<4 \text { surging }
\end{array}
$$

where $\xi_{m}$ is the Iribarren parameter using the mean wave period, $T_{m} \approx 0.85 T_{p}\left(T_{p}\right.$ is the peak spectral wave period):

$$
\xi_{m}=\frac{\tan \alpha}{S_{o m}^{1 / 2}}
$$

$s_{\text {om }}=2 \pi H_{s} / g T_{m}{ }^{2}$ is the deep water wave steepness. The transition from plunging to surging waves was given as:

$$
\xi_{m_{c}}=\left(6.2 P^{0.31} \tan \alpha^{0.5}\right)^{1 /(P+0.5)}
$$

The role of structure permeability (and slope) in classifying the type of breaker is unclear and for $P=0.5, N s$ becomes independent of the slope in surging waves. For shallow water conditions, the stability number in the VdM formulas was corrected using $H_{2 \%} / H_{s}=1.4$.

Based on the TS results, VML concluded that $H_{50}$ or the average wave height of the 50 highest waves can be used instead of $H_{s}$. They revised the VdM's formulas as:

$$
\begin{aligned}
& N_{50}=4.44 S^{0.2} P^{0.18} \xi_{m}^{-0.5} \quad \text { if } \quad\left(\xi_{\mathrm{m}}<\xi_{\mathrm{mc}}\right) \text { and } \cot \alpha \leq 4 \\
& N_{50}=0.716 S^{0.2} P^{-0.13} \xi_{m}^{p} \cot \alpha^{0.5} \text { if } \quad\left(\xi_{\mathrm{m}} \geq \xi_{\mathrm{mc}}\right) \text { or } \cot \alpha \geq 4
\end{aligned}
$$

where $N_{50}=H_{50} / \Delta D_{n 50}$.

Etemad-Shahidi and Bonakdar (2009) and Etemad-Shahidi and Bali (2012) tried to improve the formulas using data mining approaches and scaling arguments. EB used the VdM and VML data sets and proposed the following formulas:

$$
\begin{array}{ll}
\text { If } \xi_{m} \leq 2 & N_{50}=4.18 P^{0.16} S_{d}^{0.18} \xi_{m}{ }^{-0.53} \\
\text { If } \xi_{m}>2 & N_{50}=3.57 P^{0.2} S_{d}{ }^{0.18} \xi_{m}^{-0.24}
\end{array}
$$

For a Rayleigh distribution, they showed that $H_{50} / H_{s}=3.11 N_{w}^{0.04}-2.67$. 
The main advantages of the EB formulas compared to the previous study (Etemad-Shahidi and Bonakdar, 2009) were the accuracy and simplicity. They could resolve the issue with the role of $P$ in VdM and VML formulas. However, EB as well as Etemad-Shahidi and Bonakdar (2009) formulas, similar to previous ones, were validated only for deep water conditions and used nominal permeability value.

Effects of the water depth such as shoaling and wave breaking on the foreshore were investigated by Smith et al (2002). They concluded that $T_{m-1,0}$ and $H_{s}$ should be used in the VdM formulas for shallow water conditions. Their study was further extended by experiments of Van Gent et al. (2003) and Van Gent (2004) including foreshore slopes of $m=$ 1:30 and $m=1: 100$, and both single as well as double peaked spectra. By analyzing their own data, Smith et al. (2002) and those of VdM, VSK recalibrated the coefficients of VdM original formulas for shallow water as :

$$
\begin{aligned}
& N_{s}=8.4 P^{0.18} \xi_{m-1,0}^{-0.5}\left(S_{d} / \sqrt{N_{w}}\right)^{1 / 5}\left(H_{s} / H_{2 \%}\right) \quad \text { If } \quad \xi_{m-1,0}<\xi_{c} \quad \text { or } \quad \cot \alpha \geq 4 \\
& N_{s}=1.3 P^{-0.13} \xi_{m-1,0}^{p} \cot \alpha^{0.5}\left(S_{d} / \sqrt{N_{w}}\right)^{1 / 5}\left(H_{s} / H_{2 \%}\right) \text { if } \xi_{m-1,0} \geq \xi_{c} \text { and } \cot \alpha<4
\end{aligned}
$$

with $\xi_{c}=\left(6.46 P^{0.31} \tan \alpha^{0.5}\right)^{1 /(P+0.5)}$.

Replacing of $T_{m}$ by $T_{m-1,0}$ was later confirmed in the experiments of Prevot et al. (2012).

VSK also quantified the effect of permeability using the relative size of core material and derived the following formula (mainly for $1.25<h / H_{s}<3$ ):

$N S=1.75 \cot \alpha^{0.5}\left(1+D_{n 50 c} / D_{n 50}\right) N_{w}{ }^{-0.1} S_{d}^{0.2}$

where $D_{n 50 c}$ is the median nominal size of core material. The powers of $\cot \alpha, N_{w}$ and $S_{d}$ in this formula are similar to those of VdM one for plunging waves. However, the influence of the wave period is not present in the formulas.

Verhagen and Mertens (2009) attempted to unify the formulas for deep and shallow water and included the effects of foreshore slope and stone roundness on the stability. They recalibrated the VdM formula by using SwanOne (Verhagen et al. 2008) to estimate $H_{2 \%}$ and $T_{m-1,0}$ at the structure toe. Verhagen and Mertens (2009) proposed a stability formula which 
similar to previous ones, lack some physics. Hovestad (2005) also studied the effect of the foreshore slope on the stability of homogenous breakwaters $(P=0.6)$ and noticed that the stability decreases in a very steep $(m=1: 8)$ foreshore. Herrera et al. (2017) also conducted tests with $m=1: 50$ in surging wave conditions and reported that $N s \sim S_{d}{ }^{1 / 6}$. Van Gent et al. (2019) quantified the spreading around the mean values of measured damage to rock armored slopes. This allows for a statistical analysis of the damage to rock armored slopes and illustrates that spreading around best-estimates needs to be accounted for.

\section{The used data sets and modeling}

A data base of irregular tests including TS, VdM, VML and VSK laboratory data sets was prepared to have tests in both shallow and deep waters. In the used data sets, the measured damage was repaired after each test condition. Tests with very low damage level $\left(S_{d}<2\right)$ and very high damage level $\left(S_{d}>12\right)$, which are less common in practice (e.g. Rock Manual, 2007, CEM, 2011) were not used in the formula development, even though the formula was tested for them. A brief description of the range of governing parameters is given in Table 1 and more details are shown is the appendix.

As seen the used data base has 791 data points with $2 \leq S_{d} \leq 12$ and covers a wide range of parameters. For example, it covers tests in deep $\left(h / H_{s}>\sim 3\right)$ shallow $\left(\sim 1.75<h / H_{s}<\sim 3\right)$ and very shallow $\left(h / H_{s}<\sim 1.75\right)$. It should be highlighted that nearly all tests with depth limited conditions belong to VSK. These tests were performed with foreshore slopes of 1:30 and 1:100. The used data set covers a wide range of spectrums as well. TS used Moskowitz spectrum, VdM had mainly peaked Pearson-Moskowitz spectra; while VSK used JONSWAP, TMA and double-peaked spectrums. $T_{m-1,0}$ values were not measured during some test programs, and hence they have been estimated assuming standard relationships, i.e. $T_{p}=1.1$ $T_{m-1,0}$ for standard single-peaked spectra in deep water. The wave steepness values showed 
that the data base covers both seas and swell conditions. In the data base about $75 \%$ of the tests were performed with surging waves $\left(\xi_{m-1,0}>1.8\right)$.

Table 1. Range of parameters used for formula development

\begin{tabular}{|c|c|c|}
\hline Parameter & Symbol & Range \\
\hline Number of waves & $N_{w}$ & $500-5000$ \\
\hline slope & $\tan \alpha$ & $1: 6-1: 1.5$ \\
\hline Relative buoyant density & $\Delta$ & $0.92-2.05$ \\
\hline Permeability & $P$ & $0.1-0.6$ \\
\hline Relative crest height & $R c / H_{s}$ & $>1$ \\
\hline Wave steepness using $T_{m-1,0}$ & $s_{\text {om- } 1,0}$ & 0.003-0.088 \\
\hline Iribarren no using $T_{m-1,0}$ & $\xi_{m-1,0}$ & $0.65-8.18$ \\
\hline Relative water depth at toe & $h / H_{s}$ & $1.35-19.68$ \\
\hline relative size of core & $D_{n 50 c} / D_{n 50}$ & $0.0-1.0$ \\
\hline Armor stone gradation & $D_{n 85} / D_{n 15}$ & $1.25-2.25$ \\
\hline Damage level & $S_{d}$ & $2-12$ \\
\hline Stability number & $N_{s}$ & $1.0-4.3$ \\
\hline
\end{tabular}

The tests by VdM were performed with a very peaked wave energy spectrum and a low ratio of $T_{p}$ and $T_{m-1,0}\left(T_{p}=1.07 T_{m-1,0}\right)$ is used in his data base. For shallow water, this ratio is not valid. Hence, the few shallow water tests of VdM tests have not been used.

It should be mentioned that different methods are used for measuring the damage level: profiling the slope before and after the test (the most common method), counting the number of displaced stones and image processing. Vidal et al (2003) compared these methods and noticed that the counting method yields damage levels slightly lower than those obtained by other methods. In VML, which counts about $12 \%$ of the used data base, the counting method has been used for damage measurements. In all other used data sets (TS, VdM and VG), the 
profiling method has been used for measurement of damage. In these data sets, the average of 9 (in VdM and VSK) and ten (in TS) profiles which were about $0.1 \mathrm{~m}$ apart are reported. Another difference between the TS and other datasets is that in TS, the number of displaced units (rather than the eroded area) is estimated from profiling. Despite the fact that the various test programs used the same or similar methods to determine the input and output parameters, there may be some other effects that cause differences. Potential causes of differences could be the quality of wave generation that has improved over the years (active wave absorption, second-order wave generation, etc.) or the methods to determine the damage which may have been improved (automatized and less sensitive to human mistakes/inaccuracies). Although these potential differences cannot be excluded, they are considered acceptably small. Hence, some variability between the results obtained from different experiment is expected (see section on evaluation of formulas).

\section{Formula development}

As discussed before, the focus of the analysis is on damage levels that are commonly used for design. Hence, at first, only records with $2 \leq S_{d} \leq 12$ and $R c / H_{s}>1$ were considered in the data analysis. Following previous studies (e.g. Jafari and Etemad-Shahidi, 2012) large scale tests with $H_{s} \geq 0.5 \mathrm{~m}$ were not used in the formula development to prevent possible model confusion. Noting the advantages of M5 model tree (Wang and Witten, 1997, Bonakdar et al. 2015), it was used for formula development. Simply saying, M5 is a multi-variable piecewise regression model that can handle missing data. Compared to other data mining approaches such as ANN (eg Mase et al, 1995), it needs less trial and error and can provide compact and transparent formulas. For more details, refer to Quinlan (1992) and Wang and Witten (1997). It was assumed that $S_{d}=f\left(H, T, N_{w}, \Delta, D_{n 50}, D_{n 50 c}, \Delta\right.$, cot $\left.\alpha\right)$, where $H$ and $T$ are representative wave height and periods, respectively and $D_{n 50 c}$ is the nominal size of core material. It should be mentioned this parameter was selected because the permeability 
depends mainly on the core size (e.g. VdM, VSK). As discussed by VdM, the permeability is related to the volume of the water stored/dissipated in the trunk of structure during wave attack. Hence, other characteristics of structure composite may also influence the permeability. For example, Merli et al. (2013)'s laboratory experiments revealed that a wide graded layer has a lower permeability. In addition, Medina et al (2014) noticed that packing density influences the stability. However, for the sake of simplicity and noting that the tested structures were mostly standard (e.g. with 2-3 layers of rock, normal packing and grading), other layers' characteristics were not considered as a governing parameter.

Regarding the representative wave height and wave period, there is no consensus in the literature and different parameters have been suggested for deep and depth-limited wave breaking conditions. To be able to derive formulas that are applicable to all conditions, different parameters $\left(H_{2 \%}, H_{s}, T_{m}, T_{m-1,0}, \ldots\right)$ were tested and finally $H_{s}, T_{m-1,0}$ (at the toe of structure) and $N_{w}$ were selected. Then, dimensional analysis and physical reasoning were invoked. In other words, it was assumed that $N_{s}=f\left(\xi_{m-1,0}, \cot \alpha, N_{w}, D_{n 50 c} / D_{n 50}\right)$. It should be mentioned that initially, $P$ was used for modeling the permeability but using $D_{n 50 c} / D_{n 50}$ improved the results. The permeability of the structure affects processes such as the internal set-up of the phreatic surface, the wave run-up and wave run-down, and consequently, the velocities and pressures around individual stones in the amour layer. The size of the core material is supposed to affect the internal set-up, while the difference between an impermeable core $\left(D_{n 50 c}=0\right)$ and a permeable core is considered as well. The applied tests are for structures without or a rather standard (thin) underlayer. Of course, the use of a single parameter $\left(D_{n 50 c}\right)$ to characterize the permeability is a simplification, but it is likely that the size of the core material is indeed the most important one. As indicated in tests by Van Gent et al. (2017), the thickness of the underlayer and the size of the material of the underlayer also slightly affects the stability. Therefore, the presented results are valid for standard underlayers with a thickness of 2 to 3 stone diameters. As noted by Van der Meer et al. 
(2017) very thick filters ( filter layer thickness $=2 D_{n 50}$ ) can increase the $P$ value of a revetments up to $0.15-0.2$, i.e. $\sim 10 \%$ decrease in the required rock size.

After dividing the data to train $(70 \%)$ and test $(30 \%)$ subsets, different functional forms were tested. Finally, the following function that was physically sound and simpler was selected:

$N_{s}=3.9 C_{p} N_{w}{ }^{-1 / 10} S_{d}{ }^{1 / 6} \xi_{m-1,0^{-1 / 3}} \quad$ if $\xi_{m-1,0} \geq 1.8 \quad$ (surging waves)

$N_{s}=4.5 C_{p} N_{w}{ }^{-1 / 10} S_{d}{ }^{1 / 6} \xi_{m-1,0}{ }^{-7 / 12} \quad$ if $\xi_{m-1,0}<1.8 \quad$ (plunging waves)

where $C p$ is the coefficient of permeability defined as:

$C_{p}=\left[1+\left(D_{n 50 c} / D_{n 50}\right)^{3 / 10}\right]^{3 / 5}$

The validity range of Eq. 10 is given in Table 1 . The $90 \%$ confidence band is \pm 0.19 for Eq. $10 \mathrm{a}$ and \pm 0.15 for Eq. 10b. Compared to most previous formulas, Eq. 10 is compact and physically sound. It clearly shows that Iribarren number affects the stability and its influence increases when waves become plunging. When the Iribarren number increases (due to increase of the structure slope or wave period) the stability number decreases. Increase in the wave period gives more energy and time to water jet to run over the structure slope and erode it. This effect is more pronounced for plunging waves compared to surging waves.

The splitting parameter in Eq. 10 is $\xi_{m-1,0}$ with a critical value of 1.8 . As discussed by Bhattacharya et al. (2007), the critical value is obtained by minimizing the error and does not necessarily have a physical meaning. Nevertheless, Eq. 10 clearly shows that M5 algorithm successfully splits between different types of breakers by selecting at a realistic value (see also Van der Meer and Janssen, 1994). The obtained exponents for the governing parameters are close to those suggested by EB. Eq. 10 shows that the stability number is correlated with the damages level raised a power of $1 / 6$ which matches with those suggested by Herrera et al. (2017). However, it is slightly lower than those suggested before (VdM, VSK, EB). 
The main advantaged of the Eq. 10 compared to formulas of Etemad -Shahidi and Bonakdar (2009) and EB are: (a) it has been validated for both deep and shallow water conditions with a larger database/wider range and hence is more accurate (b) the structure permeability is characterized by physical parameters rather than nominal permeability, $P(\mathrm{c})$ it is simpler as Etemad-Shahidi and Bonakdar (2009) provided six formulas and EB formulas are based on

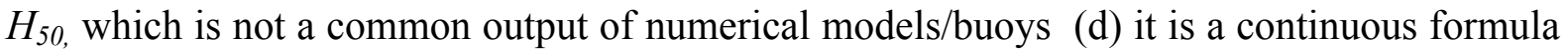
as both Eqs. $10 \mathrm{a}$ and $10 \mathrm{~b}$ give the same stability number when $\xi_{m-1,0}=1.8$ for all types of rock armored structures.

The provided formula for the permeability coefficient is also physically sound as the stability increases with permeability which itself depends on the size of core material. This permeability coefficient reduces the uncertainty introduced by selecting a specific $P$ value for a structure (especially for structures that do not exactly match with the $D_{n 50 c} / D_{n 50}$ values used to introduce nominal permeability values of $0.1,0.5$ and 0.6 ).

Eq. 10 was further modified to incorporate the effect of foreshore slope, in depth-limited wave breaking conditions, $h / H_{s}<3$ as:

$N_{s}=3.9 C_{p} N_{w}{ }^{-1 / 10} S_{d}{ }^{1 / 6} \xi_{m-1,0}{ }^{-1 / 3}(1-3 m)$ if $\xi_{m-1,0} \geq 1.8$ (surging waves)

$N_{s}=4.5 C_{p} N_{w}{ }^{-1 / 10} S_{d}{ }^{1 / 6} \xi_{m-1,0^{-7 / 12}}(1-3 m)$ if $\xi_{m-1,0}<1.8 \quad$ (plunging waves)

The foreshore slope correction term implies that the stability number is inversely related to the foreshore slopes and $N s$ can decrease by about $10 \%$ in shallow water with a foreshore slope of 1:30. This is supported by previous findings (e.g. Verhagen and Mertens, 2009) on the difference between mild and steep foreshores conditions. As stated in Verhagen et al. (2006), in shallow water the stability depends on the phase lag between velocity and acceleration. The phase lag decreases for steeper slopes, and hence maximizing the total (inertia + drag) destabilizing force exerted by waves on the armor rocks.

\section{Evaluation of formulas}


A qualitative comparison of measured and predicted stability numbers of (790) small scale tests is shown in Figure 1. As shown, the developed formula can reproduce the tests successfully without any systematic error within a wide range of stability no. The limited scatter reflects the skill of the formula for the various data sets (TS, VdM, VML and VKS).

(a)

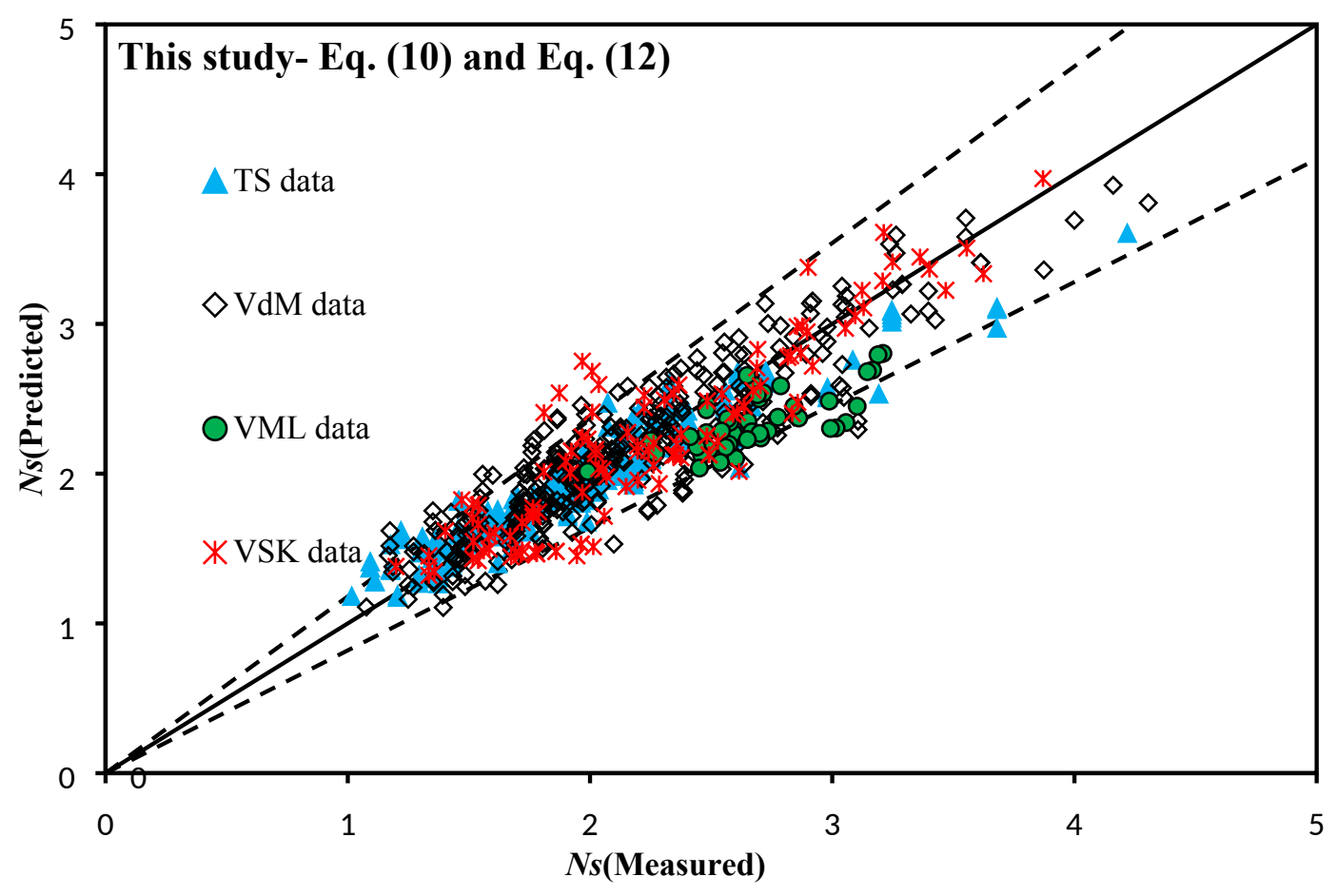

(b) 


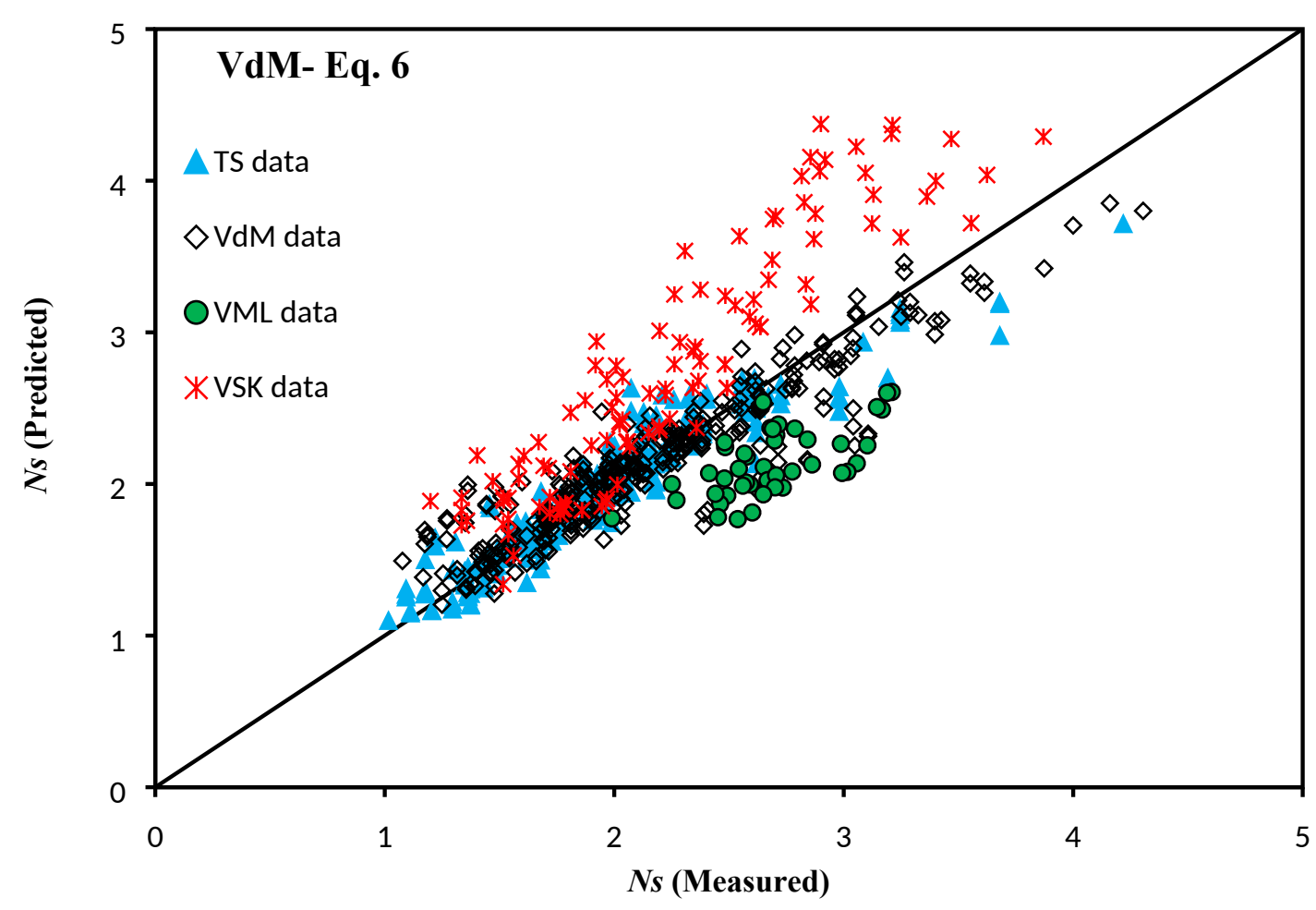

(c)

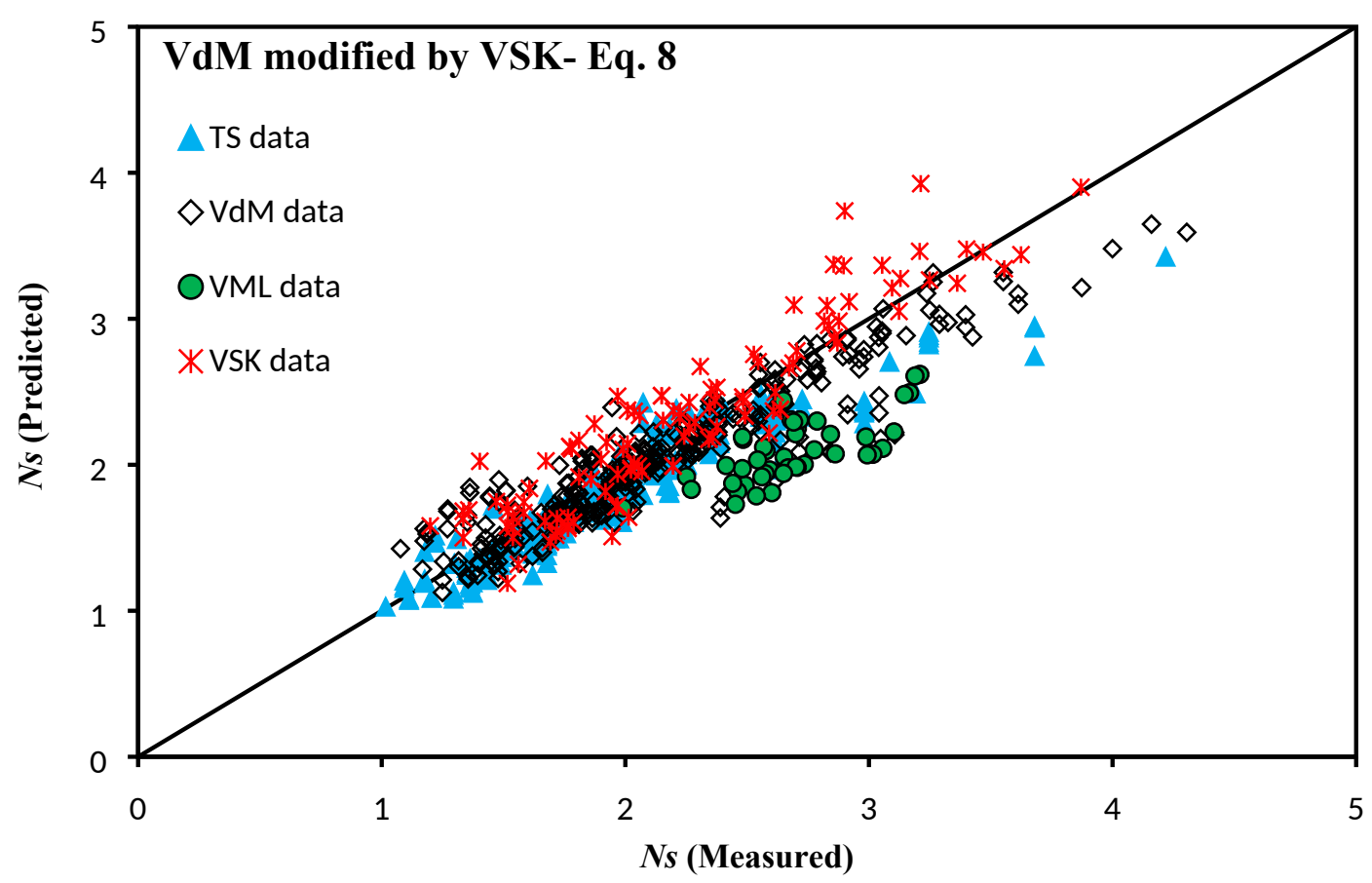

Fig. 1 Comparison between the measured and predicted stability numbers using different formulas, (a) this study, (b) VdM, (c) VdM modified by VKS; $2 \leq S_{d} \leq 12$. The dash lines indicate $90 \%$ confidence band. 
The accuracy of the predictions was quantified using accuracy metrics such as the discrepancy ratio $(D R)$ and the scatter index $(S I)$ defined as:

$$
\begin{aligned}
& D R=\frac{1}{n} \sum_{i=1}^{n}\left(p_{i} / m_{i}\right) \\
& S I=\frac{\sqrt{\frac{1}{n} \sum_{i=1}^{n}\left(p_{i}-m_{i}\right)^{2}}}{\bar{m}_{i}} \times 100
\end{aligned}
$$

where $p_{i}$ and $m_{i}$ denote the predicted and measured values, respectively. The number of observations is $n$ and the bar denotes the mean value.

Table 2 displays these metrics as well as the correlation coefficient (CC) of different formulas. It should be noted that the used small scale database includes both deep and depthlimited wave breaking conditions. Hence, only formulas that are developed for both conditions are compared.

Table 2. Accuracy metrics of different formulas, small scale tests

\begin{tabular}{cccc}
\hline Formula & $D R$ & $S I(\%)$ & $C C$ \\
\hline VdM & 1.02 & 13.4 & 0.87 \\
VdM modified by VKS & 0.96 & 12.8 & 0.90 \\
This study & 1.0 & 11 & 0.92 \\
\hline
\end{tabular}

It is noteworthy that no significant influence of the wave spectrum type on the results was observed, which is an indication that the spectral mean wave period takes the shape of the spectra into account properly. It is also important to note that the difference between the model's performance in deep and depth-limited wave breaking conditions was marginal, another indicator of robustness of the developed formulas. However, the performance of the model was slightly lower when applied to the VML data and $D R$ value reduced to 0.9 . All (44) VML tests were surging waves in deep water condition. Further analysis showed the VdM formula also underestimates $(D R=0.8)$ the stability number of VML's dataset. It is 
speculated that this is partly due to different techniques used for damage measurement (e.g. Vidal et al 2003). The other reason could be a potential effect of the $T_{p} / T_{m}$ ratio in this data set which is about 1.07, less than the typical range of 1.1-1.25.

The model was also verified using large scale data with $H_{s} \geq 0.5 \mathrm{~m}$. There are 16 large scale deep water tests in the VdM data set, mostly with surging conditions and permeable structures. Figure 2 shows the comparison between measured and predicted stability number using the developed formula.

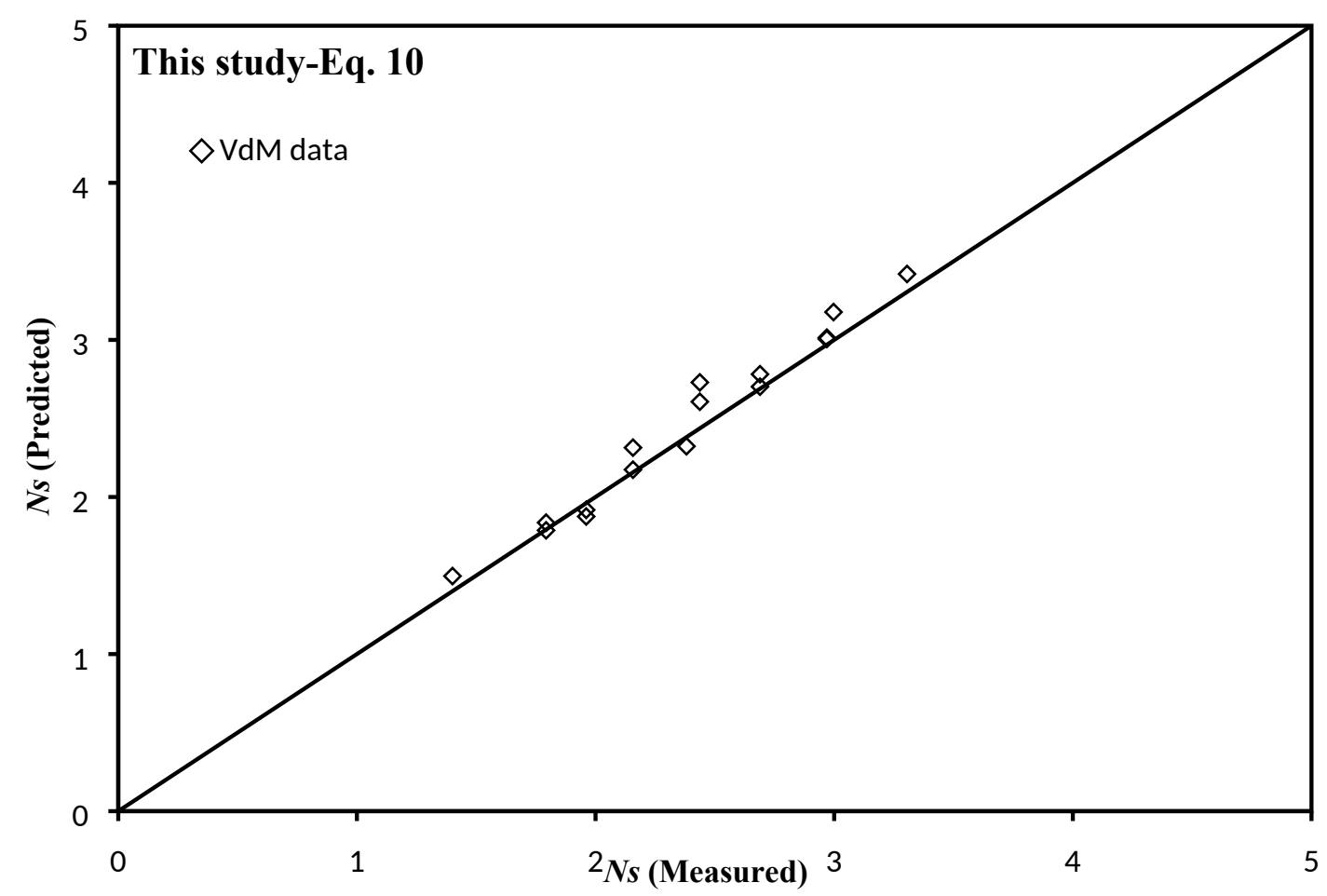

Figure 2. Comparison between measured and predicted stability numbers using Eq. 10, large scale data. Solid line indicates perfect agreement.

It shows that the formula matches the data well and that there is no significant bias in the results. The accuracy metrics of different applicable formulas are also given in Table 3 . This table shows that the VdM formula performs marginally better than Eq. 10 in large scale tests in deep water. This can be because these tests have been used for the calibration of the VdM formula while they were not used in the development of Eq. 10.

Table 3. Accuracy metrics of different formulas, large scale tests in deep water 


\begin{tabular}{cccc}
\hline Formula & $D R$ & $S I(\%)$ & $C C$ \\
\hline VdM & 1.00 & 3 & 0.93 \\
EB & 0.93 & 8 & 0.93 \\
VML & 1.02 & 4 & 0.93 \\
VdM modified by VKS & 0.94 & 5.9 & 0.93 \\
Eq. 10 & 1.03 & 5 & 0.92 \\
\hline
\end{tabular}

As mentioned before, the focus of the study was to develop a formula for design conditions, i.e. $2 \leq S_{d} \leq 12$ (Rock Manual, 2007). The conducted laboratory tests cover a wider range of damage ie $0<S_{d} \leq 62$, even though damage levels more than 14-16 are considered as unacceptable or failure for all types of rubble mound structures. In order to evaluate the generalization capacity of the developed formulas, it was applied to those tests $\left(0<S_{d}<2\right.$ and $12<S_{d} \leq 62$ ) as well. Figure 3 shows the scatter plot and Table 4 displays the accuracy metrics in this case.

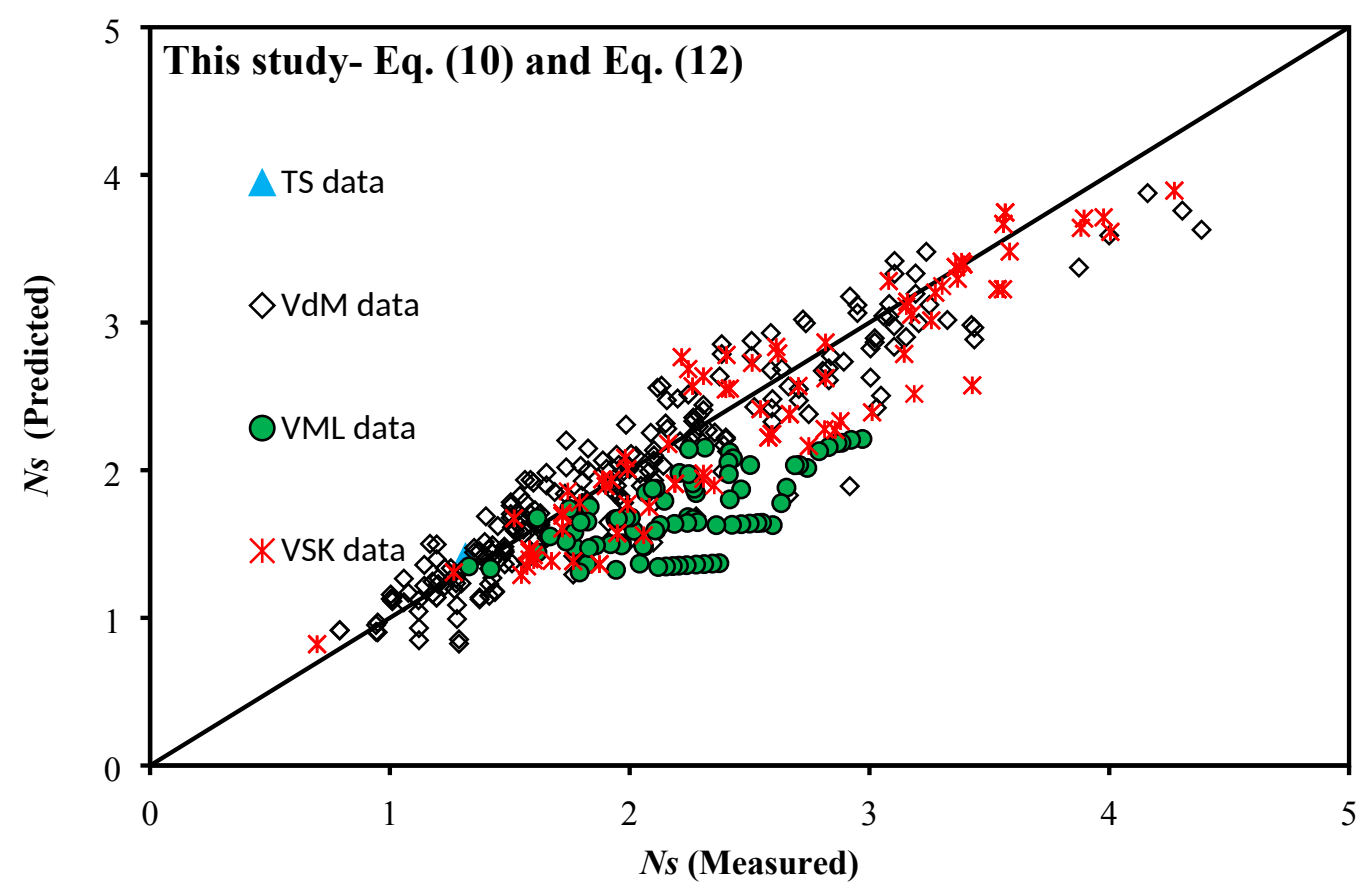


Figure 3. Comparison between measured and predicted stability numbers, $0<S_{d}<2$ or $12<$ $S_{d} \leq 62$. Solid line indicates perfect agreement.

Table 4. Accuracy metrics of different formulas, $0<S_{d}<2$ or $12<S_{d} \leq 62$

\begin{tabular}{cccc}
\hline Formula & $D R$ & $S I(\%)$ & $C C$ \\
\hline VdM & 1.01 & 22.3 & 0.86 \\
VdM modified by VKS & 0.93 & 18.2 & 0.88 \\
This study & 0.96 & 14.5 & 0.91 \\
\hline
\end{tabular}

As seen, the developed formulas are precise in this wider range of damage level, even though not calibrated for that range.

The general relationship between the stability number and other governing parameters can be written as $N_{s} \sim C_{p} N_{w}{ }^{-1 / 10} S_{d}^{1 / 6} \xi_{m-1,0^{-a}}$. Rewriting this expression yields:

$N s \sim C_{p} N_{w}{ }^{-1 / 10} S_{d}{ }^{1 / 6} \cot \alpha^{a} S_{m-1,0}{ }^{a / 2}$

where the value for $a$ is different for surging $(a=1 / 3)$ and plunging waves $(a=7 / 12)$. Hence:

$N s \sim C_{p} N_{w}{ }^{-1 / 10} \cot \alpha^{1 / 3} S_{d}{ }^{1 / 6} s_{m-1,0}{ }^{1 / 6} \quad$ if $\xi_{m-1,0} \geq 1.8 \quad$ (surging waves)

$N s \sim C_{p} N_{w}{ }^{-1 / 10} \cot \alpha^{7 / 12} S_{d}{ }^{1 / 6} s_{m-1,0}{ }^{7 / 24}$ if $\xi_{m-1,0}<1.8 \quad$ (plunging waves)

The expression for surging waves is similar to that of original formula of Hudson (1959), modified to include the effects of damage level, wave period, and number of waves. It should be noted that Hudson's tests were mostly short duration with $N_{w}<1000$. Hence, the effect of the number of waves/storm duration was not resolved by Hudson (1959). For depthlimited (wave breaking condition), Hudson (1959) suggested to reduce $K_{D}$ by $50 \%$ (from 4 to 2), which results in about $20 \%$ reduction in the stability number. In depth limited conditions, usually the wave height and hence the steepness decreases (compared to that of deep water). Eq. 16 also implies that the stability number decreases as the wave steepness is reduced.

In the given permeability formula, $C_{p}$ increases from 1.0 for a dike (with an impermeable core, $D_{n 50 c} / D_{n 50}=0$ ) to 1.42 for a breakwater (with a permeable core, $D_{n 50 c} / D_{n 50} \sim 0.3$ ). This increase is close to that obtained from the VSK formula (30\%) and the VdM formula (34\%) and is lower than that obtained using the Hudson (1959) formula (59\%) for which $K_{D}=1$ is 
proposed for a dike with an impermeable core .The plunging formula (Eq. 16b) is analogous to that of VSK, obtained mostly from plunging tests but omitting effects of the Iribarren number ( due to a small influence of the wave period in the data set of VSK).

The proposed stability formulas can also be rewritten for the prediction of damage level as:

$$
\begin{aligned}
& S_{d}=\left(0.26 N_{s} C_{p}{ }^{-1} N_{w}{ }^{1 / 10} \xi_{m-1,0}{ }^{1 / 3}\right)^{6}=0.26^{6} N_{s}^{6} C_{p}^{-6} N_{w}{ }^{0.6} \xi_{m-1,0}{ }^{2} \text { if } \xi_{m-1,0} \geq 1.8 \\
& S_{d}=\left(0.26 N_{s} C_{p}{ }^{-1} N_{w}{ }^{1 / 10} \xi_{m-1,0}{ }^{7 / 12}\right)^{6}=0.26^{6} N_{s}{ }^{6} C_{p}^{-6} N_{w}{ }^{0.6} \xi_{m-1,0}{ }^{7 / 2} \text { if } \xi_{m-1,0}<1.8
\end{aligned}
$$

This form of the expressions provides insight by demonstrating the relative importance of each dimensionless parameter on the damage level. For example, it implies that damage level is correlated with the stability number and coefficient of permeability raised to power of 6 . In terms of design parameters, the expressions read:

$S_{d}=0.26^{6}(\mathrm{~g} / 2 \pi) C_{p}{ }^{-6}\left(\Delta D_{n 50}\right)^{-6} H_{s}^{5} T_{m-1,0} \tan ^{2} \alpha N_{w}{ }^{0.6} \quad$ if $\xi_{m-1,0} \geq 1.8$

$S_{d}=0.26^{6}(\mathrm{~g} / 2 \pi)^{7 / 4} C_{p}{ }^{-6}\left(\Delta D_{n 50}\right)^{-6} H_{s}{ }^{17 / 4} T_{m-1,0}{ }^{7 / 2} \tan ^{7 / 2} \alpha N_{w}{ }^{0.6}$ if $\xi_{m-1,0}<1.8$

As seen, these forms clearly show the relative importance design parameters (such as the armor size, wave height and period) on the damage levels.

The coefficient of variation $\left(\sigma^{\prime}\right)$ of Eq. 10 is $9 \%$ for impermeable structures and $13 \%$ for permeable ones. For design purposes, usually a conservative formula is used to consider uncertainty. For an acceptable risk level of $5 \%, 1.64 \sigma^{\prime}$ should be subtracted from the obtained stability no in a semi-probabilistic approach. More details are provided in Van Gent et al. (2019).

It is recommended to investigate the effects of other parameters on the stability such as the crest level and thickness of (filter) layers in future research. Experiments in very shallow waters and possible protype damage measurement are encouraged. Another relevant for future research is the uncertainty of design parameters due to climate change and the adaptation of structures due to climate change.

\section{Summary and Conclusions}


An extensive data base from different sources was used in this study to develop physically sound stability formulas for rock armored structures. A compact formula was developed based on the local significant wave height and spectral mean energy period of the incident waves, as well as the relative size of core material. It can be concluded that the combination of M5 model tree as a robust data mining approach as well as selection of appropriate governing variables and functional form can provide reasonable and accurate explicit formulas for the prediction of the stability number. This was achieved partly due to the use of an extensive database of irregular tests, which were used to determine the appropriate governing parameters and functional form. One benefit from the analysis presented in this study is that the permeability is quantified by using the nominal diameters of armor and core material in the stability formula.

The performance of Eq. 10 was evaluated against the measured data and those of existing stability formulas. The results revealed that the developed formulas predict the required stone size satisfactorily with a low scatter, resulting in a coefficient of variation of the stability number of $11 \%$.

The main outcomes of this study are:

- In contrast to most existing stability formulas where the nominal permeability $(P)$, which is not directly related to the physical characteristics of structure, is used; the proposed coefficient of permeability incorporates the effect of permeability by using the relative size of the core to armor material $\left(D_{n 50 c} / D_{n 50}\right)$.

- A robust formula was derived for the stability of rock armored structures under wave loading in both deep and depth-limited wave breaking conditions within common design ranges. The range of validity is given in Table 1.

- The stability formula was extended (Eq. 12) to include effects of the foreshore slope in depth-limited wave breaking conditions. 
- The stability formula was validated with both large scale tests and a wider range of damage level (even beyond the failure of conventional simple sloped rubble mound structures) reported in the literature.

- The $90 \%$ confidence band of the formula was given to account for the uncertainty in the estimation of stability number.

- Hints and notes were provided for practitioners in appendix A.

\section{Acknowledgments}

We thank the University of Waikato for their comprehensive and freely available WEKA software. The authors thank J.W. van der Meer and C. Vidal for proving the databases of rubble-mound structures. We are also grateful to anonymous reviewers for their fruitful comments. 


\section{Appendix A1. Practical notes}

Numerical models (e.g. SWAN, SwanOne) are often used for wave transformation towards the toe of structures. In this case, care should be taken in defining the breaker index as a fixed high value (say 0.8) may results in overestimation of the deign wave height in depth-limited wave breaking condition. The output of many numerical models is $H_{m 0}$, the spectral wave height; that could be higher than $H_{1 / 3}$, especially for swell conditions. If required, empirical formulas of Muttray and Martinez (2017) can be used to convert $H_{m 0}$ to $H_{1 / 3}$ noting that the power of wave height in the formula developed for the inside of surf zone should be 1.5 (personal communications).

If wave transforming is not conducted numerically, then (for straight linear foreshore bed slopes and perpendicular wave attack) Hofland et al. (2017) proposed an approximation that can be used to estimate the spectral mean wave period at the toe $\left(T_{m-1,0}\right)$ :

$$
\begin{aligned}
& \frac{T_{m-1,0}}{T_{m-1,0, \text { deap }}}-1=6 \exp (-6 \hat{h})+0.25 \exp (-0.75 \hat{h}) \\
& \hat{h}=\frac{h}{H_{\text {s,deap }}}\left(\frac{1}{100 m}\right)^{0.2}
\end{aligned}
$$

To transfer the wave height to shallow water, the method by Goda (2000) as described in Rock Manual (2007), can be used as the first estimate. Alternatively, the following rule of thumb (obtained from regression of VSK data) can be used:

$$
H_{s} / H_{\text {s deep }} \approx 0.4+0.2\left(h / H_{\text {s deep }}\right) \quad \text { for } h / H_{\text {s deep }}<3
$$

Finally, similar to the formula of VSK, the relative size of the core material needs to be known for the estimation of stability number. Prior to the final design, the following rules of thumb can be used as the first guess: $D_{n 50 c} / D_{n 50}=1 / H_{s}$ with $D_{n 50 c}=0.38 \mathrm{~m}(1-300 \mathrm{~kg})$. 
Appendix A2. Parameters' ranges and number of records used in this study. Estimated values are denoted by *.

\begin{tabular}{|c|c|c|c|c|c|}
\hline & TS & $\mathrm{VdM}$ & VML & VSK & Total \\
\hline$H_{s}(\mathrm{~cm})$ & $3.1-12.2$ & $4.61-118$ & $6.67-16.1$ & $4.1-18.3$ & $3.1-118$ \\
\hline$H_{2 \%}(\mathrm{~cm})$ & $4.3-17.0 *$ & $6.5-165.2^{*}$ & $9.3-22.5$ & $5.4-23.4$ & $4.3-165.2$ \\
\hline$T_{p}(\mathrm{~s})$ & $1.12-1.58^{*}$ & $1.33-5.10$ & $1.0-1.63$ & $1.1-13.01$ & $1.0-13.01$ \\
\hline$T_{m}(\mathrm{~s})$ & $0.95-1.35$ & $1.24-4.40$ & $0.89-1.49$ & $0.90-2.03$ & $0.89-4.40$ \\
\hline$T_{m-1,0}(\mathrm{~s})$ & 1.04-1.48* & $1.21-4.64 *$ & $0.91-1.48^{*}$ & $1.03-5.12$ & $0.91-5.12$ \\
\hline$N_{w}$ & $500-5000$ & $1000-3000$ & 1000 & $492-5172$ & $492-5172$ \\
\hline$h(\mathrm{~cm})$ & 61 & $40-500$ & 50 & $9.4-44$ & $9.4-500$ \\
\hline $\cot \alpha$ & $2.0-6.0$ & $1.5-6.0$ & 1.5 & $2.0-4.0$ & $1.5-6.0$ \\
\hline$D_{n 50}(\mathrm{~cm})$ & $1.64-3.28$ & $3.32-21.0$ & 2.95 & $2.20-3.60$ & $1.64-21.0$ \\
\hline$D_{n 50 c}(\mathrm{~cm})$ & 0.0 & $0.0-6.3$ & 0.58 & $0.0-1.0$ & $0.0-6.3$ \\
\hline$\Delta$ & 1.70 & $0.92-2.05$ & 1.7 & $1.65-1.75$ & $0.92-2.05$ \\
\hline$P$ & 0.1 & $0.1-0.6$ & 0.45 & $0.1-0.5$ & $0.1-0.6$ \\
\hline$R c / H_{s}$ & $>1$ & $1.12-7.59$ & $1.49-3.6$ & $>1$ & $>1$ \\
\hline$s_{\text {om }}$ & $0.01-0.05$ & $0.004-0.064$ & $0.041-0.081$ & $0.022-0.063$ & $0.004-0.081$ \\
\hline$S_{\text {om-1,0 }}$ & $0.011-0.041$ & $0.002-0.069$ & $0.039-0.092$ & $0.001-0.038$ & $0.001-0.092$ \\
\hline$\xi_{o m}$ & $0.78-4.46$ & $0.67-7.58$ & $2.35-3.29$ & $1.04-3.70$ & $0.67-7.58$ \\
\hline$\xi_{m-1,0}$ & $0.85-4.76$ & $0.64-8.05$ & $2.20-3.37$ & $1.29-15.73$ & $0.64-15.73$ \\
\hline$h / H_{s}$ & $5.01-19.68$ & $3.1-17.35$ & $3.10-7.49$ & $1.28-6.70$ & $1.28-19.68$ \\
\hline$D_{n 50 c} / D_{n 50}$ & 0 & $0.0-1.0$ & 0.2 & $0.0-0.45$ & $0.0-1.0$ \\
\hline$S_{d}$ & $2-12$ & $0.32-33.0$ & $0.1-9.66$ & $0.35-62$ & $0.1-62$ \\
\hline$N_{s}$ & $1.02-4.22$ & $0.79-4.38$ & $1.33-3.21$ & $0.7-4.27$ & $0.7-4.38$ \\
\hline
\end{tabular}

Number

298

567

127

207

1199 
Appendix A3. Worked example

Noshahr's breakwater information is used in this example. The design conditions are:

$H_{s}=3.7 \mathrm{~m}, T_{m}=10 \mathrm{~s} T_{m-1,0}=11.8 \mathrm{~s}, N_{w}=2880(8 \mathrm{hrs}$ storm $), h=7 \mathrm{~m}, m=1: 100, \rho_{s}=2700$

$\mathrm{kg} / \mathrm{m}^{3}, \rho_{w}=1010 \mathrm{~kg} / \mathrm{m}^{3}$, cot $\alpha=2$ and $S_{d}=3$.

$\Delta=(2700-1010) / 1010=1.67$

$s_{\text {om- } 1,0}=3.7 /\left(1.56 \times 11.8^{2}\right)=0.017$

$\xi_{m-1,0}=0.5 / 0.13=3.83>1.8$ surging wave

Use $D_{n 50 c}=0.38 \mathrm{~m}($ core size $1-300 \mathrm{~kg})$

$D_{n 50 c} / D_{n 50} \approx 1 / H_{s}=0.27$ ( first guess)

$C_{p}=\left[1+\left(D_{n 50 c} / D_{n 50}\right)^{3 / 10}\right]^{3 / 5}=\left[1+(0.27)^{3 / 10}\right]^{3 / 5}=1.36$

$h / H_{s}=7 / 3.7=1.9<3$, hence Eq. 12a should be used.

$N_{s}=3.9 C_{p} N_{w}{ }^{-1 / 10} S_{d}{ }^{1 / 6} \xi_{m-1,0^{-1 / 3}}(1-3 m)=3.9 \times 1.36 \times 2880^{-1 / 10} \times 3^{1 / 6} \times 3.83^{-1 / 3} \times(1-0.03)=1.78$

$D_{n 50}=H_{s} /(\Delta N s)=3.7 /(1.67 \times 1.78)=1.24 \mathrm{~m}$

$D_{n 50 c} / D_{n 50}=0.38 / 1.21=0.31 \neq 0.27$ N.G. iterate

$C_{p}=1.38, N_{s}=1.8, D_{n 50}=1.23 \mathrm{~m}, D_{n 50 c} / D_{n 50}=0.38 / 1.23=0.31 \mathrm{OK}$

$W_{50}=2.7 \times 1.23^{3}=5.0$ tons

The estimated armor weights using different formulas for this example are given below:

\begin{tabular}{|c|c|}
\hline Hudson $\left(K_{D}=3.5\right)$ & 4.2 tons \\
\hline VdM & 6.6 tons \\
\hline EB & 5.7 tons \\
\hline VdM modified by VSK & 6.1 tons \\
\hline VSK & 4.8 tons \\
\hline Eq. (12) & 5.0 tons \\
\hline
\end{tabular}

A confidence interval of 5-95\% will result in rock weight varying between 3 to 9 tons in this example. In other words, to ensure having less than $5 \%$ chance of $S_{d}>3$, the $W_{50}$ should be 9 tons in this example (see also Rock Manual 2007). 


\section{References}

Ahrens. J.P., 1970. The influence of breaker type on riprap stability Proc. of the 12th ICCE, Washington USA. Chapter 95.

Ahrens, J.P. , 1975. Large wave tank tests of riprap stability CERC. Technical Memorandum No. 51, USA.

Bhattacharya., B., Price, R.K., Solomatine, D.P., 2007. Machine learning approach to modeling sediment transport. Journal of Hydraulic Engineering, ASCE, 133, 440-450.

Bonakdar, L., Oumeraci, H., Etemad-Shahidi, A., 2015. Wave load formulae for prediction of wave-induced forces on a slender pile within pile groups, Coastal Engineering, 102, 49-68.

Coastal Engineering Manual (CEM). 2011, Coastal Engineering Research Center, Department of Army Corps of Engineers, US, Chapter VI, Part 5.

Erdik, T. 2009, Fuzzy logic approach to conventional rubble mound structures design. Expert Systems with Applications, 36, 4162-4170.

Etemad-Shahidi, A., Bali, B., 2012. Stability of rubble-mound breakwater using H50 wave height parameter, Coastal Engineering, 59, 38-45.

Etemad-Shahidi, A., Bonakdar, L., 2009. Design of rubble mound breakwater using M'5 machine learning method .Applied Ocean Research, 31, 197-201.

Goda, Y., 2000. Random seas and design of maritime structures. In liu,p. (Ed.) Advanced series on Ocean Engineering, Vol. 15, World Scientific, Singapore, 444pp.

Herrera, M., Gomez-Martin, E., Medina, J.R., 2017. Hydraulic stability of rock armors in breaking wave conditions. Coastal Engineering, 127, 55-67.

Hofland B., Chen X., Altomare, C, Oosterlo, P. 2007, Prediction formula for the spectral wave period $T_{m-1,0}$ on mildly sloping shallow foreshores, Coastal Engineering, 123, $21-28$ 
Hovestad, M. 2005. Breakwaters on steep foreshores, MSc thesis, Delft University of Technology, Delft, The Netherlands.

Hudson, R.Y., 1958. Design of quarry stone cover layer for rubble mound breakwaters. Research Report No. 2-2, Waterways Experiment Station, Coastal Engineering Research Centre, Vicksburg, MS.

Hudson, R.Y., 1959. Laboratory investigation of rubble-mound structures, ASCE Transactions, J of the Waterways and Harbor Division, 271, 610-659.

Jafari A., Etemad-Shahidi, A. 2014. Design of ruble-mound break water, introducing a formula for the permeability, poster presented at 34th Conference on Coastal Engineering, ICCE2014, Seoul.

Kim, D.H., Park, W.S., 2005. Neural network for design and reliability analysis of rubble mound breakwaters. Ocean Engineering, 32, 1332-1349.

Mase, H., M. Sakamoto T. Sakai, 1995. Neural network for stability analysis of rubblemound breakwaters. J. of Waterway, Port, Coastal and Ocean Engineering, ASCE,121 , pp. 294-299.

Medina, J.R., Huspeth, R.T., Fassardi, C. 1994. Breakwater armor damage due to wave groups. Journal of Waterway, Port , Coastal and Ocean Engineering, 120, pp. 179198.

Medina, J.R., Molines, J., Gomez_Martin, M. 2014. Influence of armour porosity on the hydraulic stability of cube armour layers. Ocean Engineering, 88, pp. 289-297.

Merli D., Uijttewaal, W., Van den Bos, J., Roelvink, D. (2013). Stability of wide-graded rubble mounds. Journal of Waterway, Port, Coastal and Ocean Engineering, 139, 157-170.

Muttray, M., Martinez, J., 2017. The Conversion of spectral wave heights to design wave heights, Proceedings of Coast, Marine structures and Breakwaters, Liverpool, 31:2 
Prevot, G., Boucher, O., Luck, M., Benoit, M. 2012. Stability of rubble mound breakwaters in shallow water and surf zone: An experimental study, Proceedings of 33rd Conference on Coastal Engineering, Santander, Spain, 1-11.

Quinlan, J. R. 1992. Learning with continuous class. Proceeding of AI'92 (Adams and Sterling Eds).,World Scientific.

Rock Manual, 2007. The use of rock in hydraulic engineering (2nd edition), CIRIA, CUR, CETMEF, Published by C683, CIRIA, London (ISBN 978-0-86017-683-1 and 5).

Smith, G.M., Wallast, I., Van Gent, M.R.A., 2002. Rock slope stability with shallow foreshores. In: Proc., 28th International Conference on Coastal Engineering. ASCE pp. 1524-1536.

Thompson, D.M., Shuttler R.M. 1975. Riprap design for wind wave attack. A laboratory study in random waves. HR Wallingford report EX 707, Wallingford

Van der Meer. J.W., 1988a. Stability of breakwater armour layers - Design formula. Coastal Engineering, 11, $219-239$.

Van der Meer, J.W., 1988b. Rock slopes and gravel beaches under wave attack. PhD Thesis, Delft University of Technology, Delft, The Netherlands.

Van der Meer, J. W., Janssen, J. 1994. Wave run-up and wave overtopping at dikes and Revetments, Delft Hydraulics, publication no. 485.

Van der Meer, J.W., Van Gent, M.R.A., Wolters, G. and Heineke, D., 2017, New Design Guidance for Underlayers and Filter Layers for Rock Armour under Wave Attack, Proceedings of Coast, Marine structures and Breakwaters, Liverpool, 38:2.

Van Gent, M.R.A., Smale, A.J., Kuiper, C., 2003. Stability of rock slopes with shallow foreshores. Eds. J. Melby, In: Proc. Int Coastal Structures Conf., 2003, Portland, pp. $100-112$.

Van Gent, M.R.A., 2004. On the stability of rock slopes, Balkema, Keynote, Proc. NATOWorkshop on environmental friendly coastal protection structures, Varna, Bulgaria. 
Van Gent, M.R.A., Jacobsen N. G, Wolters, G. 2017. Modelling of open filters under wave loading, Proceedings of Coast, Marine structures and Breakwaters, Liverpool, 17:54.

Van Gent, M.R.A., E. de Almeida and B. Hofland, 2019. Statistical analysis of the stability of rock slopes, J. Mar. Sci. Eng. 2019, 7, doi:10.3390/jmse7030060.

Verhagen H.J., Reedijk, B., Muttray, M., 2006. The effect of foreshore slope on breakwater stability, Proc. ICCE 2006, San Diego, 4828-4840.

Verhagen H.J., Mertens, M. , 2009. Riprap stability for deep water, shallow water and steep foreshores, Proceedings of Coasts, marine structures and breakwaters conference, Edinburgh, 1-10.

Verhagen, H.J., Van Vledder, G., Eslami Arab, S., 2008. A practical method for design of coastal structures in shallow water. Proc. 31st ICCE, 1-11, Hamburg

Vidal, C., Martin, F.L., Negro, V., Gironella, J., Madrigal, B., García-Palacios, J., 2003. Measurement of armor damage on rubble mound structures: comparison between different methodologies. Proc. Coastal Structures 2003 Conference. Portland, Oregon., 189-200

Vidal, C., Medina, R. , Lomonaco, P., 2006. Wave height parameter for damage description of rubble mound breakwater. Coastal Engineering, 53, 712-722.

Wang, Y., Witten, I. H. 1997. Induction trees for predicting continuous classes. Proceeding of the Poster Papers of the European Conference on Machine Learning, Prague. University of Economics. Faculty of Informatics Statistics. 


\section{Table captions}

Table 1. Data sources, parameters' ranges and number of records used for modeling. Estimated values are denoted by $*$.

Table 2. accuracy metrics of different formulas, small scale tests

Table 3. accuracy metrics of different formulas, large scale tests

Table 4 . accuracy metrics of different formulas, $0<S_{d}<2$ or $12<S_{d} \leq 62$. 


\section{Figures Caption}

Fig. 1 Comparison between the measured and predicted stability numbers using different formulas, (a) this study, (b) VdM, (c) VdM modified by VKS; $2 \leq S_{d} \leq 12$. The dash lines indicate $90 \%$ confidence band.

Figure 2. Comparison between measured and predicted stability numbers using developed formula, large scale data. Solid line indicates perfect agreement.

Figure 3. Comparison between measured and predicted stability numbers, $0<S_{d}<2$ or $12<$ $S_{d} \leq 62$. Solid line indicates perfect agreement. 


\section{Nomenclature}

\begin{tabular}{|c|c|c|}
\hline Symbol & Name & Unit \\
\hline$\alpha$ & Structure slope angle & {$\left[{ }^{\circ}\right]$} \\
\hline$C_{P}$ & Permeability coefficient & {$[-]$} \\
\hline$\Delta=\left(\rho_{s} / \rho_{w}\right)-1$ & Relative bouyant mass density. & {$[-]$} \\
\hline $\begin{array}{c}D_{n 50}= \\
\left(M_{50} / \rho_{a}\right)^{1 / 3}\end{array}$ & $\begin{array}{l}\text { Armour equivalent cube length exceeded by } 50 \% \text { of a sample by } \\
\text { weight }\end{array}$ & [m] \\
\hline$D_{50}$ & Equivalent spherical diameter & [m] \\
\hline$D_{n 50 c}$ & $\begin{array}{l}\text { Core equivalent cube length exceeded by } 50 \% \text { of a sample by } \\
\text { weight }\end{array}$ & [m] \\
\hline$D R$ & Discrepency Ratio. & {$[-]$} \\
\hline EB & Etemad-Shahidi and Bali, 2012 & \\
\hline$h$ & Water depth at toe of the structure. & [m] \\
\hline$H_{m 0}$ & $\begin{array}{l}\text { Significant (spectral) wave height based on frequency domain } \\
\text { analysis. }\end{array}$ & {$[\mathrm{m}]$} \\
\hline$H_{2} \%$ & Average of the highest $2 \%$ of incident waves & [m] \\
\hline$H_{50}$ & $\begin{array}{l}\text { Average wave height of the } 50 \text { highest waves reaching a } \\
\text { breakwater in its useful life }\end{array}$ & {$[\mathrm{m}]$} \\
\hline$H_{s, \text { deep }}$ & Significant wave height in the deep water & {$[\mathrm{m}]$} \\
\hline$H_{s}$ & Significant wave height at toe of the structure & {$[\mathrm{m}]$} \\
\hline$K_{D}$ & Hudson stability coefficient & {$[-]$} \\
\hline$\xi_{m-1,0}$ & Iribarrn number based on $T_{m-1,0}$. & {$[-]$} \\
\hline$\xi_{o m}$ & Iribarren number based on $T_{m}$ & {$[-]$} \\
\hline$\xi_{\mathrm{mc}}$ & Transition Iribarrn number in VdM Formula & {$[-]$} \\
\hline$m$ & Foreshore slope & {$[-]$} \\
\hline $\mathrm{m}_{\mathrm{i}}$ & Measured values & {$[-]$} \\
\hline$\overline{m_{i}}$ & Average of the measured values & {$[-]$} \\
\hline$M_{50}$ & Median rock mass & [kg] \\
\hline$n$ & The number of observations & {$[-]$} \\
\hline$N$ & Coefficient for various levels of acceptable risk. & {$[-]$} \\
\hline$N_{w}$ & Number of wave attack & {$[-]$} \\
\hline$N_{s}$ & Stability number using Hs & {$[-]$} \\
\hline$N_{50}$ & Stability number using $\mathrm{H}_{50}$ & {$[-]$} \\
\hline$N_{d}$ & Number of displacement units & {$[-]$} \\
\hline$P$ & Nominal permeability & {$[-]$} \\
\hline $\mathrm{P}_{\mathrm{i}}$ & Predicted values & {$[-]$} \\
\hline$R_{c}$ & Crest freeboard & {$[\mathrm{m}]$} \\
\hline$\rho_{s}$ & Rock density & {$\left[\mathrm{kg} / \mathrm{m}^{3}\right.$} \\
\hline$\rho_{w}$ & Water density & {$\left[\mathrm{kg} / \mathrm{m}^{3}\right.$} \\
\hline
\end{tabular}




\begin{tabular}{clc}
\hline$S_{o m}=2 \pi H_{m o} / g T$ & Deep water wave steepness using $T_{\text {om }}$ & {$[-]$} \\
$S_{\text {om- }}^{2}$ & & \\
$S_{d}$ & Deep water mean wave steepness using $T_{-1,0}$ & {$[-]$} \\
$S I$ & Damage level & {$[-]$} \\
$T_{m-1,0}=m_{-1} / m_{0}$ & Scatter index & Mean energy wave period based on frequency domain \\
$T_{P}$ & Peak wave period & {$[-]$} \\
$T_{m}$ & Mean wave period & {$[\mathrm{s}]$} \\
TS & Thompson and Shuttler (1975) & {$[\mathrm{s}]$} \\
$T_{m-1,0, \text { deep }}$ & Mean energy wave period based on frequency domain analysis in & {$[\mathrm{s}]$} \\
VdM & deep water & \\
VSK & Van der Meer (1988a,b) & \\
VML & Van Gent et al. (2003) & \\
\hline
\end{tabular}

